\title{
RESEARCH
}

\section{Inhibition of caspase-6: A potential therapy for Huntington's disease}

\author{
Matthew Quinn \\ Class of 2011, Faculty of Medicine, Dalhousie University
}

\begin{abstract}
Huntington's disease (HD) is an inherited, neurodegenerative disorder that affects one in every ten thousand North Americans and for which there is currently no cure. HD is caused by an increase in the length of a CAG tri-nucleotide repeat array within the HD gene, leading to expansion of a polyglutamine tract within the huntingtin protein (htt). The mutant huntingtin protein (mhtt) is known to cause selective degeneration of neurons in the striatum resulting in movement and cognitive dysfunction. The molecular basis of mhtt-dependent HD pathology is unclear, but a recent study has shown that inhibiting cleavage of mhtt by the protease caspase- 6 is sufficient to halt death of striatal neurons and behavioral dysfunction in a rodent model of HD. In this report, current hypotheses concerning the molecular basis of HD, and existing and experimental therapies for treating HD will be reviewed with particular emphasis on the potential development of anti-caspase- 6 drugs that may provide the most promising breakthrough yet for treating this devastating disorder.
\end{abstract}

\section{Huntington's disease pathology}

Huntington's disease (HD) is an autosomal dominant, neurodegenerative disease that usually presents between the ages of 35 to 50 and for which there is currently no cure ${ }^{1}$. The primary motor symptoms of the disease include chorea, dystonia and dyskinesia, but HD is also associated with dementia, psychosis, and depression ${ }^{2}$. Pathologically, HD is characterized by the selective degeneration of GABA-releasing spiny neurons in the striatum ${ }^{3}$. A lesser amount of neuronal death is also seen in the cerebral cortex, hippocampus and thalamus. Overall brain atrophy is also a common feature ${ }^{4}$.

HD is caused by an expansion of a polyglutamine repeat track near the amino-terminus of the huntingtin protein (htt) that arises from an increase in the length of the CAG tri-nucleotide repeat array encoding this portion of the protein ${ }^{2,5}$. The wildtype Huntingtin gene contains between 6 and 35 CAG repeats, while those containing more than 36 are defined as HD alleles ${ }^{6}$. The expanded polyglutamine repeat in the mutant huntingtin protein (mhtt) induces a conformational change in the protein that causes the formation of intracellular aggregates. Although these insoluble aggregates typically present themselves as nuclear inclusions, a hallmark feature of HD, cytoplasmic forms have been identified ${ }^{7,8}$. Immunohistochemical studies have revealed that only the amino-terminus of mhtt is contained within these inclusions, suggesting that mhtt is cleaved preceding aggregation ${ }^{9}$. In vitro experiments using a cellular model of HD have demonstrated that cells containing amino-terminal cleavage fragments of mhtt with longer polyglutamine repeats are associated with increased susceptibility to cytotoxicity ${ }^{10}$. The results of this study directly support the observation that HD patients diagnosed with alleles containing higher numbers of CAG repeats are more likely to have an earlier age of disease onset ${ }^{6}$.
There are currently five predominant hypotheses to explain how a genetic abnormality in the HD allele results in neuronal dysfunction and the clinical manifestations of HD (Figure 1). First, HD aggregates become highly ubiquinated in an attempt by the ubiquitin-proteasome system(UPS) to degrade and clear them from the cell ${ }^{11}$. Ultimately their abundance overwhelms this cellular response, leading to dysregulation of the UPS and the accumulation of toxic intracellular fragments. Second, aggregation of mhtt in the nucleus has been shown to sequester transcription factors, such as p53, cAMP response element binding protein (CREB-binding protein), specificity protein 1 and TATA-binding protein ${ }^{12-15}$. Their sequestration leads to a large disruption of gene expression, which impairs normal cellular functioning. Third, excitotoxicity has been shown to contribute to HD pathogenesis. Excitotoxicity is caused by the overstimulation of N-methyl-D-aspartic acid (NMDA)

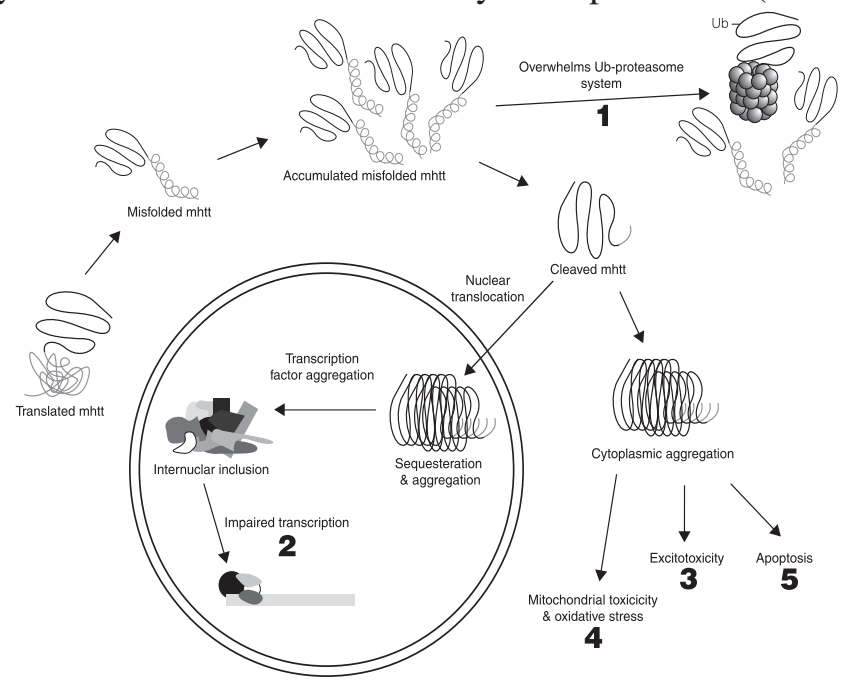

Figure 1. The major pathological mechanisms involved with Huntington's Disesase: Impairment of the ubiquitin-proteasome system (1), transcription dysregulation (2), excitotoxicity (3), mitochondrial toxicity and oxidative stress (4), and apoptosis (5). Figure adapted from Landles and Bates, $2004^{52}$. 
and $\alpha$-amino-3-hydroxy-5-methylisoxazole-4-propionic acid (AMPA) receptors by glutamate. Excitotoxicity results in a large influx of intracellular calcium, the generation of reactive oxygen species, the release of cytochrome $\mathrm{c}$ from the mitochondria and the initiation of apoptosis ${ }^{16}$. Postmortem analyses of the brains of HD patients reveals a significant reduction in the expression of NMDA receptors, implying that the cells expressing these receptors have already died due to excitotoxicity ${ }^{17}$. In animal models there is additional evidence for the involvement of excitotoxicity in HD pathology. It has been shown that there is decreased expression of the major astroglial glutamate transporter (GLT1) in the striatum of a rodent model of HD, which leads to decreased glutamate uptake from the synapse ${ }^{18}$. In addition, it has been shown that there is an increased release of glutamate in the striatum of HD mice ${ }^{19}$. Both of these events lead to an increase in synaptic glutamate concentration, which results in excitotoxicity of striatal neurons. Fourth, pathological analyses of the brains of HD patients reveals increased accumulation of lipofuscin, a marker of lipid peroxidation, and increased levels of 8-hydroxy-2-deoxyguanosine, a molecular marker for oxidative damage to DNA. Both of these markers indicate the involvement of oxidative stress in $\mathrm{HD}^{20-22}$. Also, it has been shown that the expression and activity of nitric oxide synthase increases in the striatum of HD mice, implying that there is increased synthesis of nitric oxide, which is able to contribute to oxidative stress ${ }^{23}$. Fifth and finally, the accumulation of caspase cleavage fragments of mhtt represents an early pathological event in the brains of HD patients ${ }^{24}$ and increased levels of biomarkers for apoptosis have been detected in postmortem HD brains ${ }^{25}$. The caspase-mediated apoptotic pathway may become activated as a consequence of excitotoxicity, oxidative stress or dysregulation of the UPS, and it likely provides positive reinforcement back onto these events, leading to increased propagation of the neurodegenerative process ${ }^{16,26}$.

The emerging picture of the underlying pathophysiological mechanism preceding HD is very complex, consisting of many interconnected pathways. In spite of the growing body of knowledge surrounding HD pathology, few compounds have been developed to prevent neurodegeneration. The following section will present current therapies used in the treatment of HD, highlighting the fact that few of them have proven useful in slowing disease progression.

\section{Current therapies for Huntington's disease}

To date, most therapeutic strategies for treating HD have focused solely on addressing the associated symptoms including chorea, dystonia, dyskinesia, depression and psychosis. Neuroleptics, such as pimozide, olanzapine, fluphenazine and haloperidol, function by antagonizing the effect of dopamine in the central nervous system and have been used widely in the treatment of chorea ${ }^{27}$. High doses of neuroleptics, however, have been associated with unwanted side effects including impairment of oculomotor function, orolingual function, swallowing and fine motor tasks ${ }^{28,29}$. NMDA receptor antagonists, such as amantadine and riluzole, have also been shown to reduce chorea in HD patients ${ }^{30,31}$. In addition to their symptomatic benefit, these compounds may also prove useful in slowing HD progression by blocking excitotoxicity. Few clinical studies have been done to investigate the efficacy of compounds at reducing dystonia in HD patients, but generally anticholinergic drugs, diazepam or botulinium toxins have been prescribed. Traditional antidepressants, such as selective serotonin reuptake inhibitors, tricyclic antidepressants and sedatives, have been used in the treatment of depression caused by $\mathrm{HD}^{32}$. Interestingly, although $40 \%$ of HD patients report experiencing depression, only $2 \%$ of these patients receive treatment for it, indicating that it is a feature of HD that commonly goes undiagnosed or under treated ${ }^{27}$. A more complete overview of the treatment options available for HD are outlined in Figure 2.

Several neuroprotective compounds, such as coenzyme Q10, remacemide, alpha-tocupherol, lamotrigine and idebenone, have undergone clinical trials in hopes of slowing HD progression; however, none of these compounds have provided significant improvements compared to control groups $^{33-36}$. Clinical studies investigating the utility of the antiapoptotic antibiotic minocycline at slowing HD progression have provided encouraging results, although reproducibility has been an issue ${ }^{37}$. Preclinical studies in a HD rodent model and in Drosophila indicate that histone deactylase inhibitors

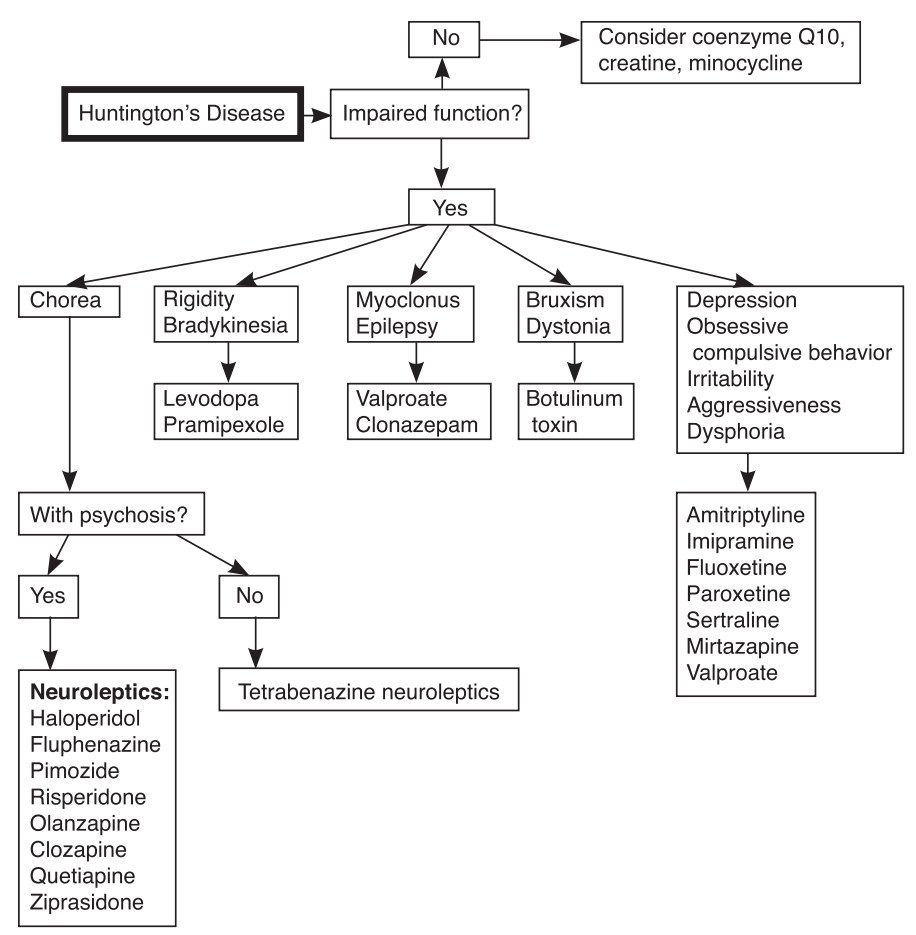

Figure 2. Overview of treatment options available for Huntigton's Disease. Figure adapted from Adam and Jankovic, 2008 ${ }^{53}$. 
(HDAC) are able to attenuate the toxic effects of mhtt by normalizing the transcriptional dysregulation associated with $\mathrm{HD}^{38}$. Recently, the HDAC phenylbutyrate has been shown to normalize mRNA levels in 10 out of $12 \mathrm{HD}$ patients in an ongoing phase II clinical trial, indicating its possible usefulness as a therapeutic intervention ${ }^{39}$. Due to the interaction of many cellular pathways, it appears likely that a combined neuroprotective strategy will be necessary in order to successfully slow HD progression. In spite of the complex pathophysiology underlying $\mathrm{HD}$, a recent study has identified an exciting new molecular event leading to the onset of HD in a rodent model.

\section{Cleavage of mhtt by caspase- 6 is necessary for the initiation of Huntington's disease}

Whatever the ultimate cause of HD, involvement of the caspase-mediated apoptopic pathway is a likely contributor to HD pathogenesis. Many cleavage sites for proteases, calpains, caspases and endopeptidases have been identified near the amino-terminus of $\mathrm{mht}^{24,40,41}$. Cleavage of mhtt by caspase- 3 and caspase- 6 occurs in vitro, and caspase cleavage fragments are present early on in HD patients ${ }^{24,42}$. Selective site-directed mutagenesis of all five caspase cleavage sites in mhtt inhibits cytotoxicity in a cellular model of $\mathrm{HD}^{43}$. Interestingly, although transgenic mice expressing a truncated amino-terminal fragment of mhtt display intracellular inclusions and behavioral deficits ${ }^{44,45}$, they do not display neurodegeneration and HD pathology ${ }^{46}$. This suggests that it is a specific proteolytic cleavage fragment of mhtt that directly results in cellular pathology and not any arbitrary amino-terminal mhtt fragment.

Development of a caspase-6 resistant HD mouse demonstrated that cleavage of mhtt by caspase- 6 is necessary for the initiation of striatal neurodegeneration and behavioral pathology in a rodent model of $\mathrm{HD}^{47}$. These mice have a selective mutation in the caspase- 6 cleavage site in mhtt and thus the mutant protein cannot be cleaved by caspase- 6 . The results of this study showed that mice containing a wild-type allele and mice containing a caspase- 6 resistant HD allele were indistinguishable in terms of brain weight and striatal volume, whereas mice with a caspase- 6 sensitive mutant HD gene exhibited a significant decrease in striatal volume and striatal neuronal cell counts. The characteristic formation of intranuclear inclusions was delayed in the caspase- 6 resistant mice compared to the caspase- 6 sensitive HD mice. Also, caspase- 6 resistant HD mice exhibited increased tolerance to NMDA-receptor stimulation compared to HD mice. This is consistent with the observation that excitotoxicity plays an important role in HD pathogenesis and shows that the caspase6 cleavage fragment of mhtt increases susceptibility to excitotoxic stress ${ }^{48}$. Caspase- 6 resistant HD mice did not show any behavioral deficits on the rotarod test compared to wildtype animals up to 10 months, whereas caspase- 6 sensitive
HD mice showed a severe deficit beginning at 2 months. Also, caspase- 6 resistant HD mice were indistinguishable from wild-type mice when assessed in an open-field trial, whereas caspase- 6 sensitive HD mice exhibited a hypokinetic behavior.

The authors of this study hypothesized that the inability of caspase-6 resistant HD mice to generate the caspase-6 cleavage fragment of mhtt was the reason for their delayed HD onset. An alternative hypothesis suggests that mutating the amino acid sequence of mhtt may have caused a conformational change in the protein, leading to a reduction in its toxic effects. The authors argue that this explanation is unlikely for two reasons. First, both htt and mhtt have been shown to possess antiapoptotic effects during embryonic development. Mice that do not express htt do not survive past embryonic day $7.5^{49,50}$. Caspase-6 resistant HD mice were able to undergo normal embryonic development, which demonstrates that caspase6 resistant mhtt retained its anti-apoptotic effects. Second, caspase- 6 resistant HD mice were resistant to excitotoxicity, which is consistent with the observation that htt is protective against excitotoxic insults ${ }^{51}$. Both of these observations demonstrate that mutating the caspase- 6 cleavage site in mhtt did not affect its physiological function and presumably its three dimensional configuration.

\section{Conclusion}

HD is a devastating, inherited, neurodegenerative disorder. Currently, no cure exists for HD and modern therapies have minimal benefit, attempting solely to decrease HD symptoms. In spite of an increasingly complex pathological network underlying HD, caspase-6 cleavage of mhtt represents an early event triggering disease progression. The caspase6 study suggests that inhibition of caspase- 6 might be a novel therapeutic target in preventing HD or slowing its progression.

\section{ACKNOWLEDGEMENTS}

The author would like to acknowledge Dr. Karim Mukhida and Dr. Melanie Dobson for their help and suggestions in writing the manuscript.

\section{REFERENCES}

1. Bates GP, Davies SW. Transgenic mouse models of neurodegenerative disease caused by CAG/ polyglutamine expansions. Mol Med Today 1997;3:508-515.

2. Harper PS. Huntington's Disease, 2nd ed. London: W. B. Saunders, 1996.

3. Cicchetti F, Prensa L, Wu Y, Parent A. Chemical anatomy of striatal interneurons in normal individuals and in patients with Huntington's disease. Brain Res Rev 2000;34:80-101.

4. Qin $\mathrm{ZH}$, Gu ZL. Huntingtin processing and pathogenesis of Huntington's disease. Acta Pharmacol Sin 2004;25:1243-1249.

5. Huntington's Disease Collaborative Research Group. A novel gene containing 
a trinucleotide repeat that is expanded and unstable on Huntington's disease chromosomes. Cell 1993;72:971-983.

6. Myers RH, Marans KS, MacDonald ME. Huntington's disease. In: Genetic Instabilities and Hereditary Neurological Diseases (R.D. Wells \& S.T. Warren. Eds.). San Diego: Academic Press, 1998:301-323.

7. Gutekunst CA, Li SH, Yi H, Mulroy JS, Kuemmerle S, Jones R, Rye D, Ferrante RJ, Hersch SM, Li XJ. Nuclear and neuropil aggregates in Huntington's disease: relationship to neuropathology. J Neurosci 1999; 19:2522-2534.

8. Kim KJ, Yi Y, Sapp E, Wang Y, Cuiffo B, Kegel KB, Qin ZH. Aronin N, DiFiglia M. Caspase 3-cleaved N-terminal fragments of wild-type and mutant huntingtin are present in normal and Huntington's disease brains, associate with membranes, and undergo calpain-dependent proteolysis. Proc Natl Acad Sci USA 2001;98:12784-12789.

9. Davies SW, Turmaine M, Cozens BA, Raza AS, Mahal A, Mangiarini L, Bates G. From neuronal inclusions to neurodegeneration: neuropathological investigation of a transgenic mouse model of Huntington's disease. Philos Trans R Soc Lond B Biol Sci 1999;354:981-989.

10. Hackam AS, Singaraja R, Wellington CL, Metzler M, McCutcheon K, Zhang T, Kalchman M, Hayden MR. The influence of huntingtin protein size on nuclear localization and cellular toxicity. J Cell Biol 1998;141:1097-1105.

11. Ciechanover A. The ubiquitin-proteasome pathway: on protein death and cell life. EMBO J 1998;17:7151-1760.

12. Landles C, Bates GP. Huntingtin and the molecular pathogenesis of Huntington's disease. EMBO reports 2004;5:958-963.

13. Cha JH. Transcriptional dysregulation in Huntington's disease. Trends Neurosci 2000;23:387-392.

14. Sugars KL, Rubinsztein DC. Transcription abnormalities in Huntington disease. TRENDS in Genetics 2003;19:233-238.

15. Luthi-Carter R, Strand A, Petters NL, Solano SM, Hollingsworth ZR, Menon AS, Frey AS, Spektor BS, Penney EB, Schilling G, Ross CA, Borchelt DR, Tapscott SJ, Young AB, Cha J-H, Olsen JM. Decreased expression of striatal signaling genes in a mouse model of Huntington's disease. Hum Mol Genet 2000;9:1259-1271.

16. Rego AC, Oliveira CR. Mitochondrial Dysfunction and Reactive Oxygen Species in Excitotoxicity and Apoptosis: Implications for the Pathogenesis of Neurodegenerative Diseases. Neurochem Res 2003;28:1563-1574.

17. Dure LS, Young AB, Penney JB. Excitatory amino acid binding sites in the caudate nucleus and frontal cortex of Huntington's disease. Ann. Neurol 1991;30:785-793.

18. Lievens JC, Woodman B, Mahal A, Spasic-Boscovic O, Samuel D, KerkerianLe Goff L, Bates P. Impaired Glutamate Uptake in the R6 Huntington's Disease Transgenic Mice. Neurobiology of Disease 2001;8:807-821.

19. Nicniocaill B, Haraldsson B, Hansson O, O'Conner WT, Brundin P Altered striatal amino acid neurotransmitter release monitered using microdialysis in R6/1 Huntington transgenic mice. Eur J Neurosci 2001;13:206-210.

20. Browne SE, Bowling AC, MacGarvey U, Baik MJ, Berger SC, Muqit MMK, Bird ED, Beal MF. Oxidative damage and metabolic dysfunction in Huntington's disease: Selective vulnerability of the basal ganglia. Ann Neurol 1997;41:646-653.

21. Browne SE, Wheeler V, White JK, Fuller SW, MacDonald M, Beal MF Dose-dependent alterations in local cerebral glucose use associated with the huntingtin mutation in Hdh CAG knock-in transgenic mice. Soc Neurosci Abstr 1999;25:218

22. Polidori MC, Mecocci P, Browne SE, Senin U, Beal MF. Oxidative damage to mitochondrial DNA in Huntington's disease parietal cortex. Neurosci Lett 1999;272:53-56.

23. Perez-Severiano F, Escalante B, Vergara P, Rios C, Segovia J. Age-dependent changes in nitric oxide synthase activity and protein expression in striata of mice transgenic for the Huntington's disease mutation. Brain Res 2002;919:3642.

24. Wellington CL, Ellerby LM, Hackam AS, Margolis RL, Trifiro MA, Singaraja R, McCutcheon K, Salvesen GS, Propp SS, Bromm, M. Caspase cleavage of gene products associated with triplet expansion disorders generates truncated fragments containing the polyglutamine tract. J Biol Chem 1998;273:91589167.

25. Portera-Cailliau C, Hedreen JC, Price DL, Koliatsos VL. Evidence for apoptotic cell death in Huntington disease and excitotoxic animal models. $\mathrm{J}$ Neurosci 1995; 15:3775-3787.

26. Villa M, Przeborski S. Targeting programmed cell death in neurodegenerative diseases. Nature Rev Neurosci 2003:4:365-375.

27. Tyler A, Scourfield J, Morris M. Management and therapy of Huntington's disease. In: Harper PS (editor): Huntington's Disease. London: Saunders Company, 1996:161-200.
28. Dursun SM, Burke JG, Andrews H, Mlynik-Szmid A, Reveley MA. The effects of antipsychotic medication on saccadic eye movement abnormalities in Huntington's disease. Prog Neuropsychopharmacol Biol Psychiatry 2000;24:889-896.

29. Moskowitz CB, Marder K. Palliative care for people with late-stage Huntington's disease. Neurol Clin 2001;19:849-865.

30. Verhagen Metman L, Morris MJ, Farmer C, Gillespie M, Mosby K, Wuu J, Chase TN. Huntington's disease: a randomized, controlled trial using the NMDA-antagonist amantadine. Neurology 2002;59:694-699.

31. Seppi K, Mueller J, Bodner T, Brandauer E, Benke T, Weirich-Schwaiger H. Riluzole in Huntington's disease (HD): an open label study with one year follow up. J Neurol 2001;248:866-869.

32. Bonelli RM, Wenning GK, Kapfhammer HP. Huntington's disease: present treatments and future therapeutic modalities. Intl Clin Psychopharmacol 2004;19:51-62.

33. Huntington Study Group. A randomized, placebo-controlled trial of coenzyme Q10 and remacemide in Huntington's disease. Neurology 2001;57:397-404.

34. Peyser CE, Folstein M, Chase GA, Starkstein S, Brandt J, Cockrell JR, et al. Trial of d-alpha-tocopherol in Huntington's disease. Am J Psychiatry 1995;152:1771-1775.

35. Kremer B, Clark CM, Almqvist EW, Raymond LA, Graf P, Jacova C, et al. Influence of lamotrigine on progression of early Huntington disease: a randomized clinical trial. Neurology 1999;53:1000-1011.

36. Ranen NG, Peyser CE, Coyle JT, Bylsma FW, Sherr M, Day L, et al. A controlled trial of idebenone in Huntington's disease. Mov Disord 1996;11:549-554.

37. Bonelli RM, Heuberger C, Reisecker F. Minocycline for Huntington's disease: an open label study. Neurology 2003;60:883-884.

38. Butler R, Bates GP. Histone deacetylase inhibitors as therapeutics for polyglutatmine disorders. Nat. Rev. Neurosci 2006;7:784-796.

39. Borovecki $\mathrm{F}$ et al. Genome-wide expression profiling of human blood reveals biomarkers for Huntington's disease. Proc Natl Acad Sci USA 2005; 102:11023-11028.

40. Lunkes A, Lindenberg KS, Ben-Haiem L, Weber C, Devys D, Landwehrmeyer GB, Mandel JL, Trottier Y. Proteases acting on mutant huntingtin generate cleaved products that differentially build up cytoplasmic and nuclear inclusions. Mol Cell 2002;10:259-269.

41. Gafni J, Hermel E, Young JE, Wellington CL, Hayden MR, Ellerby LM. Inhibition of calpain cleavage of huntingtin reduces toxicity: accumulation of calpain/caspase fragments in the nucleus. J Biol Chem 2004;279:20211-20220.

42. Wellington CL, Ellerby LM, Gutekunst CA, Rogers D, Warby S, Graham RK, Loubser O, van Raamsdonk J, Singaraja R, Yang YZ, Gafni J, Bredesen D, Hersch SM, Leavitt BR, Roy S, Nicholson DW, Hayden MR. Caspase cleavage of mutant huntingtin precedes neurodegeneration in Huntington's disease. J Neurosci 2002;22:7862-7872.

43. Wellington CL, Singaraja R, Ellerby LM, Savill J, Roy S, Leavitt B, Cattaneo E, Hackam AS, Sharp A, Thornberry N, et al. Inhibiting caspase cleavage of huntington reduces toxicity and aggreagate formation in neuronal and nonneuronal cells. J Biol Chem 2000;275:19831-19838.

44. Davies SW, Turmaine M, Cozens BA, DiFiglia M, Sharp AH, Ross CA, Scherzinger E, Wanker EE, Mangiarini L, Bates GP. Formation of neuronal intranuclear inclusions underlies the neurological dysfunction in mice transgenic for the HD mutation. Cell 1997;90:537-548.

45. Schilling G, Becher MW, Sharp AH, Jinnah HA, Duan K, Kotzuk JA, Slunt $\mathrm{HH}$, Ratovitski T, Cooper JK, Jenkins NA, et al. Intranuclear inclusions and neuritic aggregates in transgenic mice expressing a mutant $\mathrm{N}$-terminal fragment of huntingtin. Hum Mol Genet 1999;8:397-407.

46. Slow EJ, Graham RK, Osmand AP, Devon RS, Lu G, Deng Y, Pearson J, Vaid K, Bissada N, Wetzel R. Absence of behavioral abnormalities and neurodegeneration in vivo despite widespread neuronal huntingtin inclusions. Proc Natl Acad Sci USA 2005;102:11402-11407.

47. Graham RK, Deng Y, Slow EJ, Haigh B, Bissada N, Lu G, Pearson J, Shehadeh J, Bertram L, Murphy Z, Warby SC, Doty CN, Roy S, Wellington CL, Leavitt BR, Raymond LA, Nicholson DW, Hayden MR. Cleavage at the caspase-6 site is required for neuronal dysfunction and degeneration due to mutant huntingtin. Cell 2006;125:1179-1191.

48. Levine MS, Klapstein GJ, Koppel A, Gruen E, Cepeda C, Vargas ME, Jokel ES, Carpenter EM, Zanjani H, Hurst RS. Enhanced sensitivity to NMDA receptor activation in transgenic and knockin mouse models of Huntington's disease. J Neurosci Res 1999;58:515-532.

49. Bates GP, Murphy KP. In: Huntington's Disease (Bates GP, Harper PS, Jones AL. Eds) Oxford, UK:Oxford University Press, 2002:387-426. 
50. Hodgson JG, Smith DJ, McCutcheon K, Koide HB, Nishiyama K, Dinulos MB, Stevens ME, Bissada N, Nasir J, Kanazawa I. Human huntingtin derived from YAC transgenes compensates for loss of murine huntingtin by rescue of the embryonic lethal phenotype. Hum Mol Genet 1996;5:1875-1885.

51. Leavitt BR, van Raamsdonk JM, Shehadeh J, Fernandes H, Murphy Z, Graham RK, Wellington CL, Raymond LA, Hayden MR. Wild-type huntingtin protects neurons from excitotoxicity. J Neurochem 2006;96:1121-1129. Epub 2006 Jan 17.

52. Landles C, Bates GP. Huntingtin and the molecular pathogenesis of Huntington's disease. Fourth in molecular medicine review series. EMBO Rep 2004;5:958-963.

53. Adam OR, Jankovic J. Symptomatic Treatment of Huntington Disease. Neurotherapeutics 2008;5:181-197.

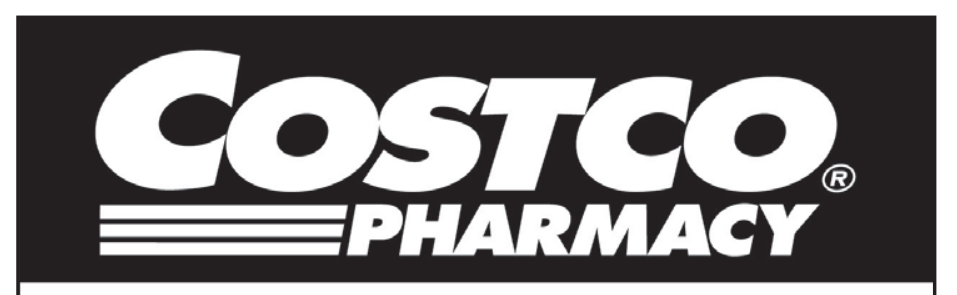

\section{Congratulation to all the Grads}

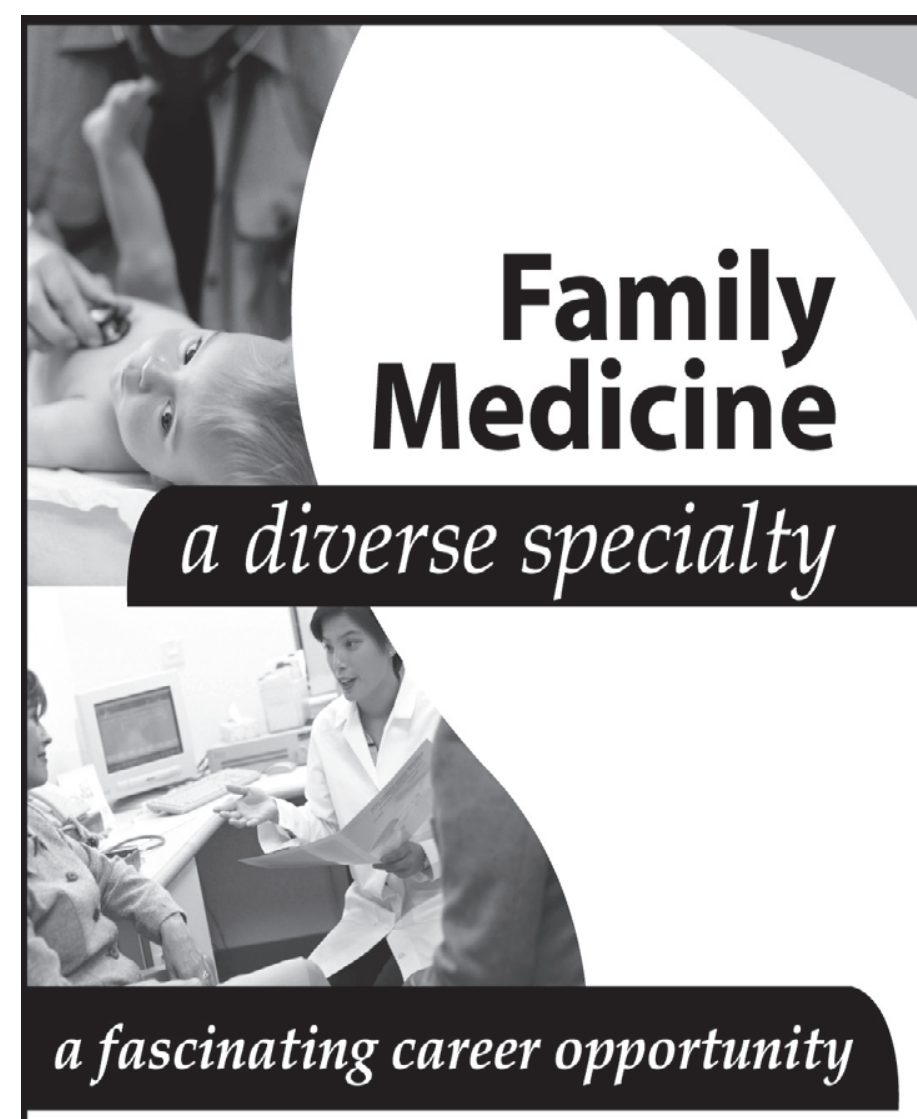

Are you one of a growing number of Canadians who recognize how important it is for individuals and families to have access to a caring personal physician?

Imagine yourself then, having a career as a family doctor, with the privilege of caring for and connecting with people in all walks of life, every day.

Imagine having the opportunity to put your training and skills to work in an urban, suburban or rural community, and having a profound impact wherever you choose to practice in Canada.

Imagine new challenges in caregiving each and every day, presented by patients of all ages with a variety of health problems.

Imagine a profession which lets you do all this and then gives you access to further training to develop special skills in areas of interest and adapt them to the needs of the community in which you work.

Stop imagining. Choose family practice -- a diverse specialty with many opportunities in teaching, research and frontline health care.

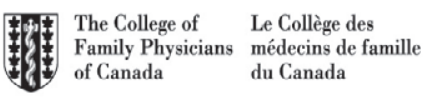

Production of this advertisment has been made possible through a financial contribution from Health Canada. The views expressed herein do not necessarily represent the views of Health Canada. 